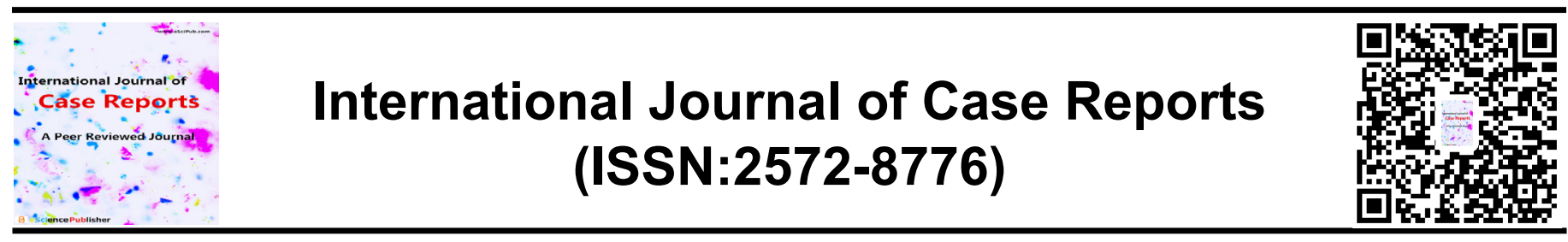

\title{
Diffuse-type tenosynovial giant cell tumour of the temporo- mandibular joint: an indication for alloplastic joint replacement
}

\author{
An-Sofie Vandeput ${ }^{1}$, MD; Michel Bila ${ }^{1}, M D ;$ Titiaan Dormaar $^{1}$, MD; Anne-Marie Delsupehe $^{2}$, \\ MD; Constantinus Politis ${ }^{1}, \mathrm{MD}, \mathrm{PhD}$ \\ ${ }^{1}$ Department of Oral and Maxillofacial Surgery, University Hospital Leuven, Leuven, Belgium; \\ ${ }^{2}$ Department of Pathology, University Hospital Leuven, Leuven, Belgium
}

\section{ABSTRACT}

A 25-year old female patient was referred to our department with a mass at the level of the right temporomandibular joint (TMJ). The patient experienced symptoms of paroxysmal pain of the TMJ and weight loss. Magnetic resonance imaging (MRI) revealed a tumour in the right masticatory space extending into the right TMJ, with invasion of the temporal bone. Surgical resection of the mass and total TMJ replacement surgery with a custom-made pros-thesis were performed. Final histological diagnosis of the resected specimen showed a dif-fuse-type tenosynovial giant cell tumour (D-TGCT). The multidisciplinary team's ${ }^{*}$ Correspondence to Author: decision was to give adjuvant radiotherapy; however, the patient declined further treatment. At 6 months follow-up, the patient had an excellent recovery with no signs of tumour recurrence on MRI. This is the first described case of D-TGCT treated with total TMJ replacement sur-gery using a custom-made alloplastic device.

An-Sofie Vandeput, MD

Department of Oral and Maxillo-Facial Surgery, University Hospital Leuven; Herestraat 49 B-3000 Leuven,Belgium

How to cite this article:

An-Sofie Vandeput; Michel Bila; Titiaan Dormaar; Anne-Marie Delsupehe; Constantinus Politis. Diffuse-type tenosynovial giant cell tumour of the temporo-mandibular joint: an indication for alloplastic joint replacement. International

Keywords: tenosynovial giant cell tumour; temporomandibular Journal of Case Reports, 2020 joint; alloplastic joint re-placement; prosthesis

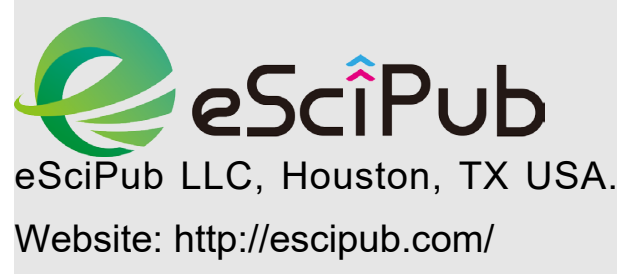




\section{Case}

A 25-year old female patient presented at our department of Oral and Maxillofacial Surgery with a recently diagnosed tumoural mass in the right masticator space. The patient had experienced symptoms of paroxysmal pain at the level of the right temporomandibular joint (TMJ) which worsened at night. Symptoms of weight loss and paraesthesia of the right maxillary nerve were also noted. Clinical examination revealed pain on palpation of the right pterygoid muscles and a reduced maximum mouth opening. On magnetic resonance imaging (MRI), a tumoural mass of $3.5 \mathrm{~cm}$ in diameter and with intraosseous components was seen in the right masticator space at the level of the TMJ (Fig. 1). TMJ arthroscopy showed an inflamed and hypertrophic synovium on the medial capsule with red-browncoloured villi (Fig. 2). A core biopsy was harvested during arthroscopy, and pathological examination revealed an intra-articular tenosynovial giant cell tumour (Fig. 3).

Two months after initial presentation, surgical resection of the mass and total TMJ replacement surgery with a custom-made Zimmer-Biomet TMJ device (Biomet microfixation, Jacksonville, FL, USA) was performed. Pathology confirmed the diagnosis of a diffuse-type tenosynovial giant cell tumour (D-TGCT) of the TMJ.
Microscopically, an infiltrative and diffuse hypercellular tumour consisting of mononuclear cells and multinucleated giant cells was seen. Positive resection margins were present at sites where the tumour was peeled off of the dura mater during surgery.

Adjuvant radiotherapy was proposed after multidisciplinary deliberation; however, the patient declined further treatments. Therefore, strict observation with no further interventions was planned. At 6 months follow-up, no signs of tumour recurrence were seen on MRI. Functional outcomes were favourable and the patient reported improvements regarding speech, eating, and masticatory function.

\section{Literature}

Tenosynovial giant cell tumours (TGCTs) are a group of benign intra-articular and soft tissue tumours that can affect any synovial joint. ${ }^{1}$ These lesions arise from the synovium-lined tendon sheaths that are present in joints and can be classified into localized and diffuse subtypes. Cytogenetic studies investigating their pathogenesis have shown a number of chromosomal structural and numeric aberrations associated with TGCT. More specifically, clonal structural aberrations affecting the $1 \mathrm{p} 11$ to $1 \mathrm{p} 13$ region and trisomies of chromosomes 5 and 7 were found in these studies. ${ }^{[1-3]}$

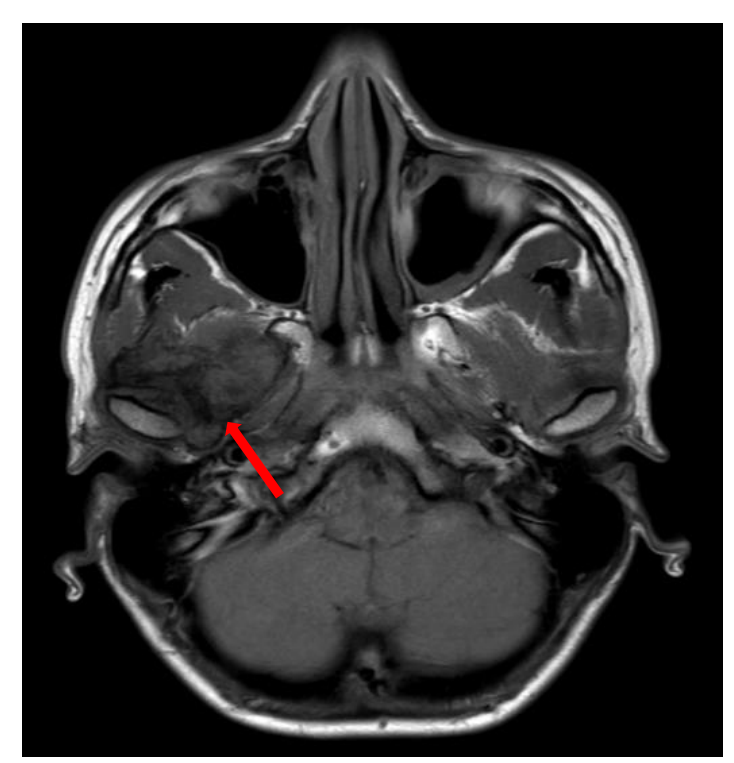

Fig. 1. Axial MRI image of the tumoural mass at the level of the right masticator space. 


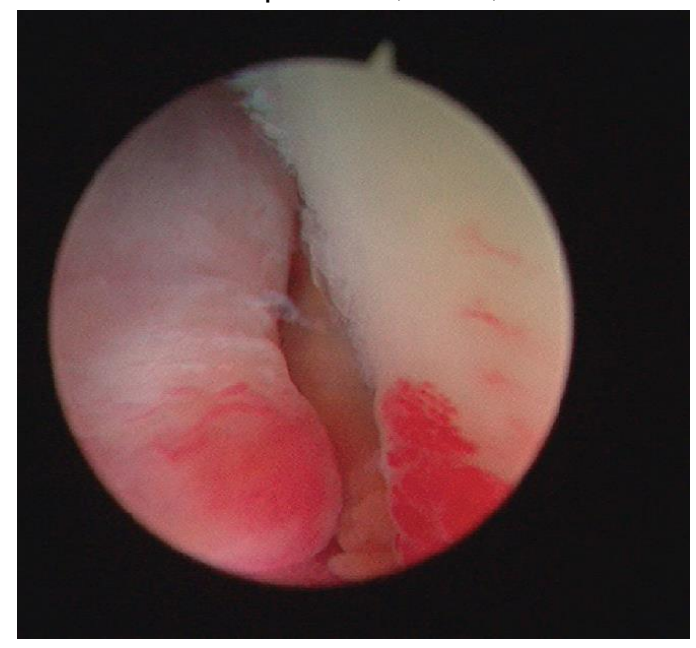

Fig. 2. Arthroscopy image showing an inflamed capsule with villi indicative of a tenosynovial giant cell tumour

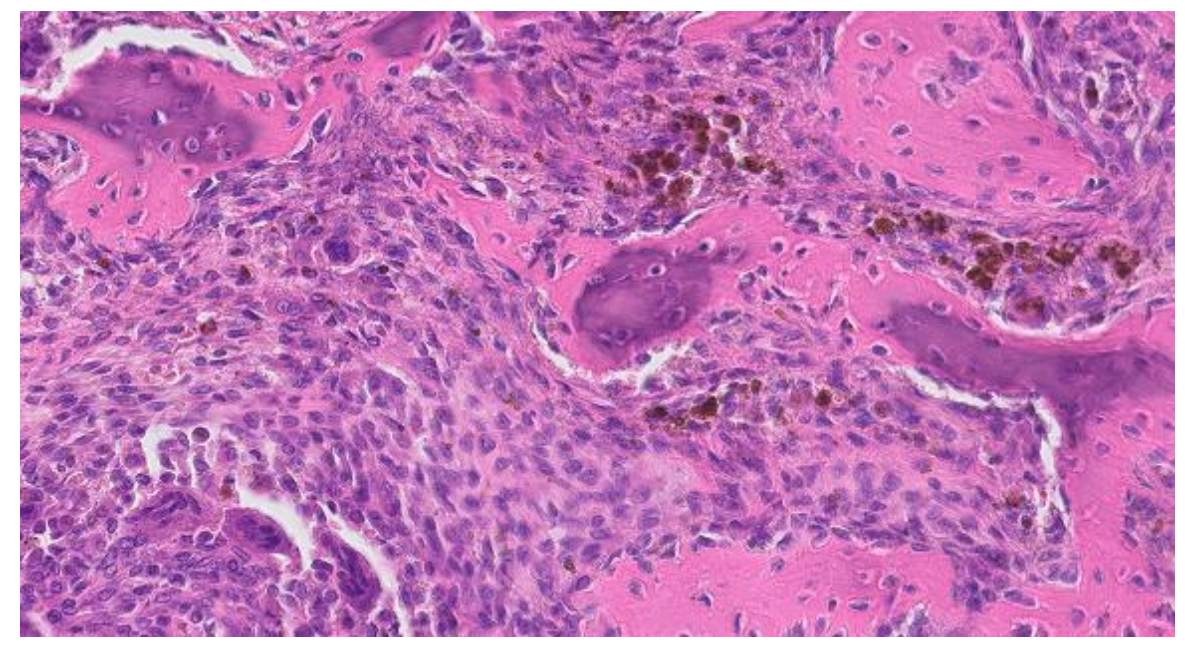

Fig. 3. Diffuse-type, hypercellular tenosynovial giant cell tumour showing mononuclear cells and multinucleated giant cells and haemosiderin deposits (H\&E staining; original magnification, $\mathbf{x} 400$ ).

Localized TGCTs are usually indolent with a slow, progressive course. The diffuse subtypes, however, are more invasive and can cause extra-articular disease. Generally, these types of tumours occur in large weight-bearing joints such as the hip, the knee, and the ankle, and present as a painless, slowly growing mass. ${ }^{[4]}$ On MRI, typical findings for D-TGCTs are an enlarged mass that extends away from the joint and hemosiderin deposits inside the lesion. ${ }^{[5]}$ TGCTs of the TMJ are very rare and usually of the diffuse subtype, causing symptoms such as limited mouth opening, painless pre-auricular swelling or trismus, bone destruction, and invasion of adjacent structures. ${ }^{[6-8]}$ Treatment of D-
TGCTs consists of removal of the lesion via a complete synovectomy. However, if complete resection is not possible, additional treatments with radiation therapy, radiation synovectomy, total joint arthroplasty, immune therapy, or cryosurgery may be necessary. ${ }^{[4,9]}$

In this case, the patient underwent total TMJ reconstruction with a custom-made Zimmer-Biomet TMJ device after complete resection of the lesion, the condylar process, and the articular disc. In the literature, no other cases have been described in which total TMJ replacement surgery with a custom-made device was performed on a patient with D-TGCT. Our patient had an excellent functional recovery after TMJ 
replacement surgery with a patient-specific alloplastic prosthesis, with no postoperative complications and an improved quality of life.

\section{Acknowledgements}

None.

\section{Conflicts of interest and funding statement}

This research did not receive any specific grant from funding agencies in the public, commercial, or not-for-profit sectors.

\section{References}

[1]. Lucas DR. Tenosynovial giant cell tumor: case report and review. Arch Pathol Lab Med 2012;136;901-6.

[2]. Fletcher JA, Henkle C, Atkins L, et al. Trisomy 5 and trisomy 7 are nonrandom aberrations in pigmented villonodular synovitis: confirmation of trisomy 7 in uncultured cells. Genes Chromosomes Cancer 1992;4;264-6.

[3]. Nilsson M, Hoglund M, Panagopoulos I, et al. Molecular cytogenetic mapping of recurrent chromosomal breakpoints in tenosynovial giant cell tumors. Virchows Arch 2002;441;475-80.

[4]. Verspoor FGM, Mastboom MJL, Weijs WLJ, et al. Treatments of tenosynovial giant cell tumours of the temperomandibular joint: a report of three cases and a review of literature. Int J Oral Maxillofac Surg 2018;47;1288-94.

[5]. Mastboom MJL, Verspoor FGM, Verschoor AJ, et al. Higher incidence rates than previously known in tenosynovial giant cell tumors. Acta Orthop 2017;88;688-94.

[6]. Wang JG, Liu J, He B, et al. Diffuse Tenosynovial Giant Cell Tumor Around the Temporomandibular Joint: An Entity With Special Radiologic and Pathologic Features. Journal of oral and maxillofacial surgery : official journal of the American Association of Oral and Maxillofacial Surgeons 2019;77;1022.e1-.e39.

[7]. Hamza A, Gidley PW, Learned KO, et al. Uncommon tumors of temporomandibular joint: An institutional experience and review. Head \& neck 2020.

[8]. Bridge JA, Hogendoorn P, Fletcher CDM, et al. WHO Classification of Tumours of Soft Tissue and Bone. 4th ed. Lyon: International Agency for Research on Cancer; 2013. 1 online resource (471 pages) $p$.

[9]. Mastboom MJL, Palmerini E, Verspoor FGM, et al. Surgical outcomes of patients with diffusetype tenosynovial giant-cell tumours: an

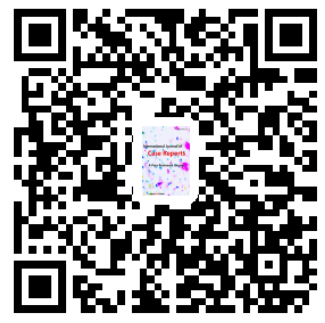

international, retrospective, cohort study. The Lancet Oncology 2019;20;877-86. 